\title{
The Efficacy of Biologic Therapy for the Management of Palmoplantar Psoriasis and Palmoplantar Pustulosis: A Systematic Review
}

\author{
Isabelle M. Sanchez · Eric Sorenson · Ethan Levin · Wilson Liao
}

Received: September 22, 2017 / Published online: November 15, 2017

(c) The Author(s) 2017. This article is an open access publication

\begin{abstract}
Introduction: Palmoplantar psoriasis (PP) and palmoplantar pustulosis (PPP) are diseases affecting the hands and/or feet that can cause marked physical discomfort and functional disability. The tumor necrosis factor-alpha antagonists adalimumab, etanercept, and infliximab, the interleukin (IL)-17A inhibitors ixekizumab and secukinumab, and the IL-23 or IL-12/IL-23 inhibitors guselkumab and ustekinumab have been well studied for the treatment of moderate to severe plaque psoriasis.
\end{abstract}

Enhanced content To view enhanced content for this article go to http://www.medengine.com/Redeem/ 1CCCF0605FC14A88.

Isabelle M. Sanchez and Eric Sorenson contributed equally.

Electronic supplementary material The online version of this article (doi:10.1007/s13555-017-0207-0) contains supplementary material, which is available to authorized users.

I. M. Sanchez $(\bowtie) \cdot$ E. Levin · W. Liao Department of Dermatology, University of California San Francisco, San Francisco, USA e-mail: isanch7@uic.edu

I. M. Sanchez

University of Illinois at Chicago College of

Medicine, Chicago, USA

E. Sorenson

Division of Dermatology, University of California

Los Angeles, Los Angeles, USA
Less is known about the efficacy and safety of these agents for the treatment of PP (hyperkeratotic and pustular forms) and PPP. The aim of this review was to investigate the efficacy of biologic therapy for the treatment of hyperkeratotic PP, pustular PP, and PPP.

Methods: A systematic search of the medical electronic databases (Medline, Embase, and Cochrane Library) was conducted to identify studies or case reports which both used biologic therapy for the treatment of hyperkeratotic PP, pustular PP, and PPP and reported treatment outcomes.

Results: The systematic search identified 579 published articles, of which 44 were included in the analysis. Seven of the articles involved randomized placebo-controlled trials, two were open label trials, and the remaining were cohort studies, case series, or case reports. In the randomized controlled trials on the treatment of hyperkeratotic PP, adalimumab, guselkumab, infliximab, ixekizumab, and secukinumab each demonstrated superiority to placebo at 16,16 , 14,12 , and 12 or 16 weeks, respectively $(p<0.05)$. For the treatment of pustular PP, ustekinumab $45 \mathrm{mg}$ was not superior to placebo at 12 and 16 weeks, respectively $(p>0.05)$, although an open label study demonstrated that four of five patients on a therapeutic regimen of ustekinumab $90 \mathrm{mg}$ achieved clinical clearance at 16 weeks. For the treatment of PPP, etanercept and ustekinumab $45 \mathrm{mg}$ were not superior to placebo at 12 and 16 weeks, respectively 
$(p>0.05)$. A combined analysis of studies for hyperkeratotic PP demonstrated that 94.7\%, $90.0 \%, 82.5 \%, 89.1 \%$, and $86.7 \%$ of patients experienced an improvement of at least 50\% upon treatment with adalimumab, guselkumab, ixekizumab, secukinumab, and ustekinumab, respectively. In a combined analysis of case reports examining PPP, infliximab showed the greatest efficacy at $100.0 \%$ clinical improvement of patients from case reports, followed by ustekinumab at $58.8 \%$ clinical improvement. Few serious adverse events were reported, but several were reported in patients treated with infliximab or secukinumab.

Conclusion: Biologic therapy is effective and well-tolerated for the treatment of hyperkeratotic PP, but less data are available on the treatment of pustular PP or PPP. Adalimumab, guselkumab, ixekizumab, secukinumab, and ustekinumab all showed $>80 \%$ efficacy for the treatment of hyperkeratotic PP, while infliximab and ustekinumab showed moderate efficacy for the treatment of pustular PP, and infliximab was the most efficacious treatment for PPP.

Keywords: Adalimumab; Biologic therapy; Etanercept; Infliximab; Ixekizumab; Palmoplantar psoriasis; Palmoplantar pustulosis; Pustular psoriasis; Secukinumab; Ustekinumab

\section{INTRODUCTION}

Palmoplantar psoriasis (PP) is a chronic, debilitating disease of the palms and/or soles that affects $11-39 \%$ of psoriasis patients [1-3]. The morphology of PP can range from thick, hyperkeratotic plaques with fissuring to pustular lesions of the palms and/or soles, and PP is often classified into subtypes based on this morphologic distinction [4, 5]. Hyperkeratotic PP refers to sharply defined erythematous scaly plaques with overlying hyperkeratosis and without the presence of sterile pustules, predominantly at the palms and/or soles [6]. Pustular PP is a variant that includes macroscopic sterile pustules and erythema with intermixed yellow-brown macules localized to the palms and/or soles [6]. PP causes greater physical discomfort and functional disability than psoriasis limited to other body areas, and it is often recalcitrant to treatment [2].

Palmoplantar pustulosis (PPP) is a bilateral, symmetric dermatosis that also affects the hands and/or feet and is clinically distinguished from PP based on the absence of psoriasis at other body sites and a predilection for histologic involvement of the acrosyringium (the terminal duct of eccrine sweat glands) $[6,7]$. Pustular PP and hyperkeratotic PP mostly occur concomitantly with psoriasis at other body areas, while PPP consists of pustular lesions typically limited to the palms and/or soles that appear on a clear, non-erythematous background [6-8]. However, whether PPP can be considered a clinical spectrum of plaque psoriasis or whether it is an independent disease is open to much debate. Consequently, in the literature, pustular PP and PPP are often not well distinguished. Some studies have identified the involvement of the acrosyringium as being more specific to PPP $[7,9]$. Demographically, PPP is characterized by a female predominance and strong association with smoking, whereas no such associations exist for pustular PP [6, 7]. Interestingly, in individuals with PPP, nicotine is thought to be secreted into eccrine glands to promote inflammation and alter the local response to infection [7]. Recent genetic studies have challenged the relationship of PPP with plaque psoriasis, although both these conditions can respond to similar treatments and have a similar impact on quality of life.

Topical therapy and phototherapy are first-line modalities for the management of PP and PPP. However, the majority of patients eventually require treatment with systemic medications [3]. Traditionally, agents such as oral retinoids, methotrexate, and cyclosporin have been utilized, but these medications carry risks of adverse effects that may limit their use in clinical practice.

Biologic agents have been well studied for the treatment of moderate to severe chronic plaque psoriasis, but less is known about the efficacy of these medications for the treatment of PP and PPP. We have therefore performed a 
systematic review of the use of biologic agents for the treatment of hyperkeratotic PP, pustular PP, and PPP with the aim to provide clinicians with helpful information when considering management options for these disabling conditions.

\section{METHODS}

The biomedical and healthcare journal databases of Ovid National Library of Medicine's Medical Literature Analysis and Retrieval System (MEDLINE), Embase, and the Cochrane Library were searched to identify published articles that assessed the efficacy and safety of biologic agents for the treatment of hyperkeratotic PP, pustular PP, and PPP. The detailed search strategy is presented in Electronic Supplementary Material Fig. 2. Abstracts were screened, and articles that appeared to meet the inclusion criteria were assessed further. Reference lists of relevant articles were scrutinized to identify additional reports.

\section{Eligibility Criteria}

Publications were included if subjects were diagnosed with PP or PPP based on the assessment by the authors of each publication and if subjects received treatment with one of the currently approved biologics for psoriasis, namely, adalimumab, brodalumab, etanercept, guselkumab, infliximab, ixekizumab, secukinumab, or ustekinumab. Publications were required to report the efficacy and/or safety outcomes of the biologic treatment. Publications describing the treatment of cases of PPP induced by exposure to biologic medications were excluded due to the likely distinct pathophysiology of drug-induced PPP.

\section{Study Selection and Data Extraction}

Three reviewers (E.S., I.S., E.L.) independently conducted publication selection (Fig. 1). Any discrepancies were resolved by an additional reviewer (W.L.). Studies were categorized based on the morphology of palmoplantar lesions.
Study characteristics (author, year of publication, design, number of patients, intervention, duration of treatment, outcome, and key safety indicators) and subject characteristics (age, sex, comorbidities, morphological variant, severity at baseline, involvement of sites other than the palms and soles, and prior treatments) were extracted using a standardized data abstraction form designed for this review. Efficacy outcomes were recorded in Table 1 , defined as a $50 \%$ reduction in the PPP Area and Severity Index (PPASI-50) if available, otherwise a 75\% reduction in PPASI (PPASI-75) or an Investigator Global Assessment (IGA) score of $0 / 1$ (cleared/minimal disease) was used. If two biologics were studied in one study, both were described in Tables 1, 2, 3 and 4 under the category of the primary biologic that was studied, but the efficacy data of both biologics were used to calculate the summary of clinical improvement outcomes in Table 5. Due to the heterogeneity of outcome measures, outcomes were reported as described by the authors of each publication.

\section{Compliance with Ethics Guidelines}

This article is based on previously conducted studies and does not involve any new studies of human or animal subjects performed by any of the authors.

\section{RESULTS}

The initial search yielded 731 articles. After excluding duplicates, we screened 579 reports by title and abstract, of which identified 76 articles for full-text review. Following the full-text review, we ultimately included 44 publications reporting the use of a biologic medication in the treatment of PP and PPP in the analysis, seven and two of which were randomized controlled trials (RCTs) and open-label trials, respectively (Table 1) [10-22]. The remaining publications were case reports or case series [20-53].

A total of 722 cases of hyperkeratotic PP, 63 cases of pustular PP, and 58 cases of PPP were included in the analysis. Almost all patients in 


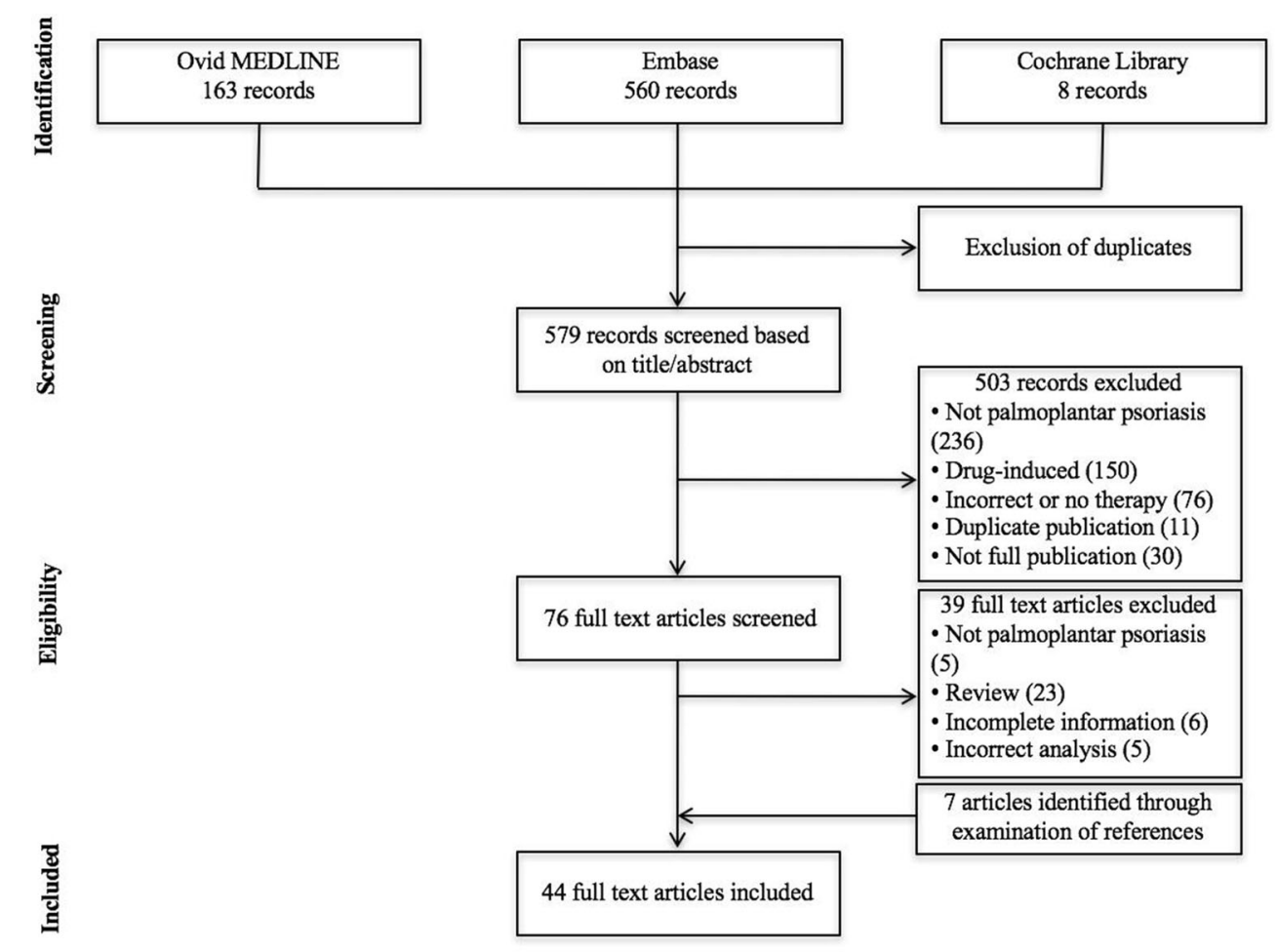

Fig. 1 Process of study selection

the included studies were adults. The specifics of age, gender, comorbidities, and previous therapies are shown in Tables 1, 2, 3 and 4. The previous use of systemic therapy was not consistently reported in all patients. Many patients received prior systemic therapy and some had received prior biologic therapy. Several subjects had responded to phototherapy, and nearly all had not responded to topical therapy.

\section{Efficacy}

The results of each publication are summarized in Tables 1, 2, 3 and 4 . The characteristics describing each study are reported in Tables S1, S2, S3, and S4. The proportion of patients demonstrating clinical improvement is reported in Table 5.

\section{Hyperkeratotic PP}

In the RCT performed by Leonardi et al. [14], a greater number of patients with hyperkeratotic PP treated with adalimumab achieved a clinical score of clear or almost clear at 16 weeks compared to patients treated with placebo $(30.6 \%$ vs. $4.3 \% ; p=0.01)$. Response was maintained at 28 weeks by $80 \%$ of these subjects. Of the patients in the RCT or case reports who were treated with adalimumab, $94.7 \%$ demonstrated an overall clinical improvement. In another RCT by Bissonnette et al. [13], a greater proportion of patients with hyperkeratotic PP treated with infliximab achieved at least a 50\% reduction in clinical severity at 14 weeks compared to patients treated with placebo $(66.7 \%$ vs. $8.3 \% ; p=0.01)$. These authors also reported that infliximab was superior to placebo in the reduction of mean area of involvement (50 decrease vs. $15 \%$ increase; $p=0.01$ ). Overall, $75 \%$ of all patients studied using infliximab demonstrated clinical improvement. In their clinical trial, Blauvelt et al. [15] observed a significant clinical clearance among those patients treated with guselkumab when compared to those receiving placebo at 16 weeks $(85.1 \%$ reaching an IGA score of 0 or $1 ; p<0.001$ ). Clinical improvement was observed in $90 \%$ of all patients studied receiving treatment with 


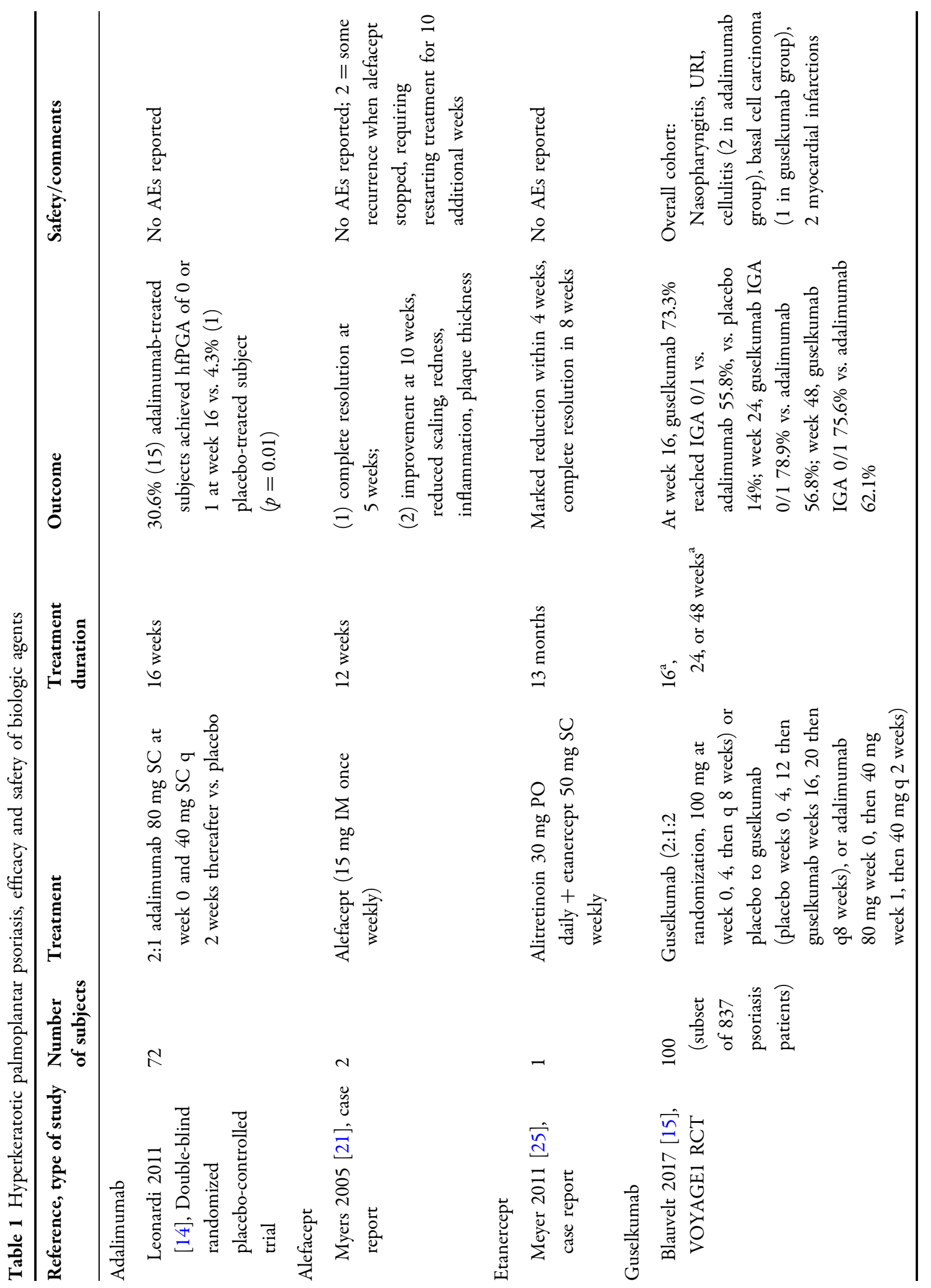




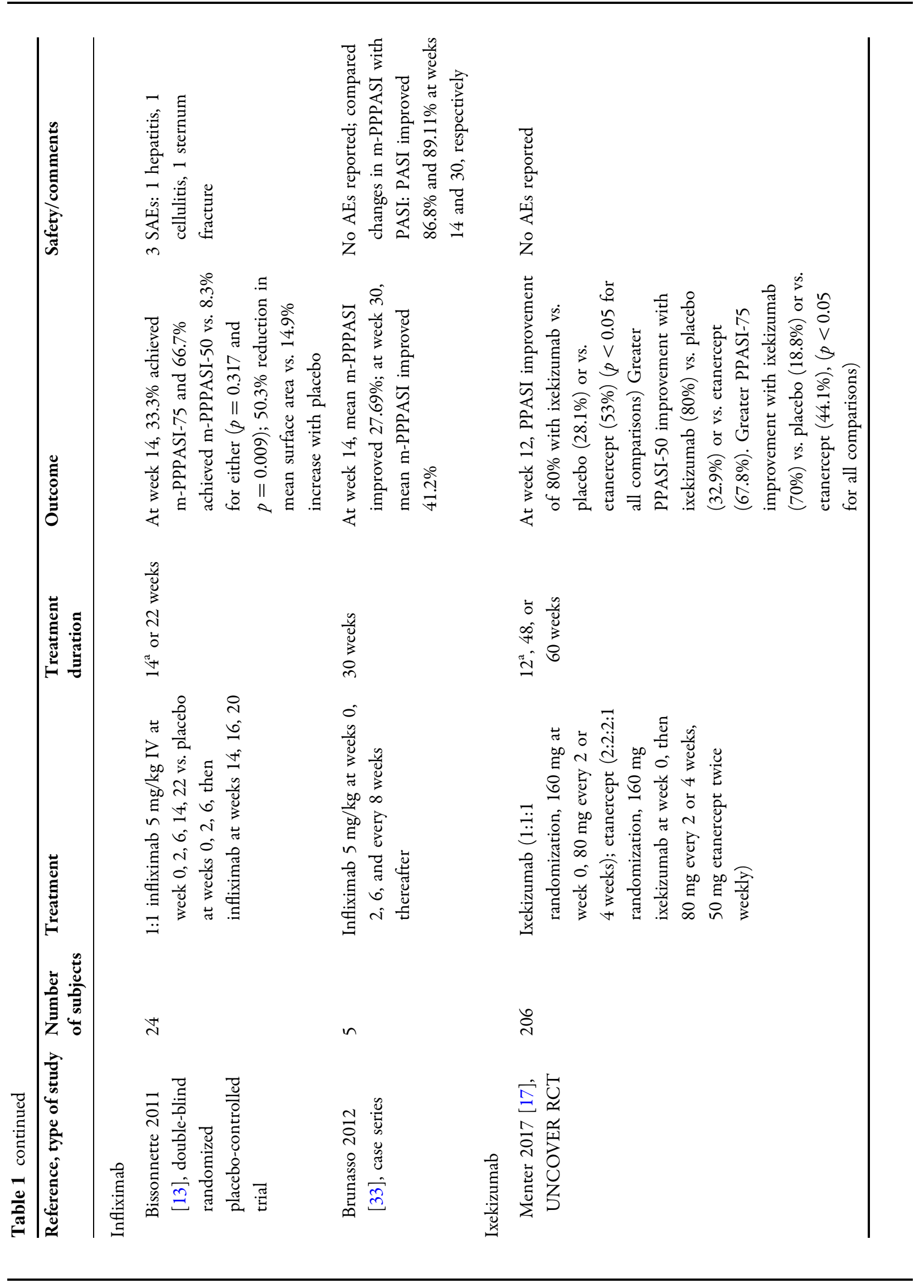




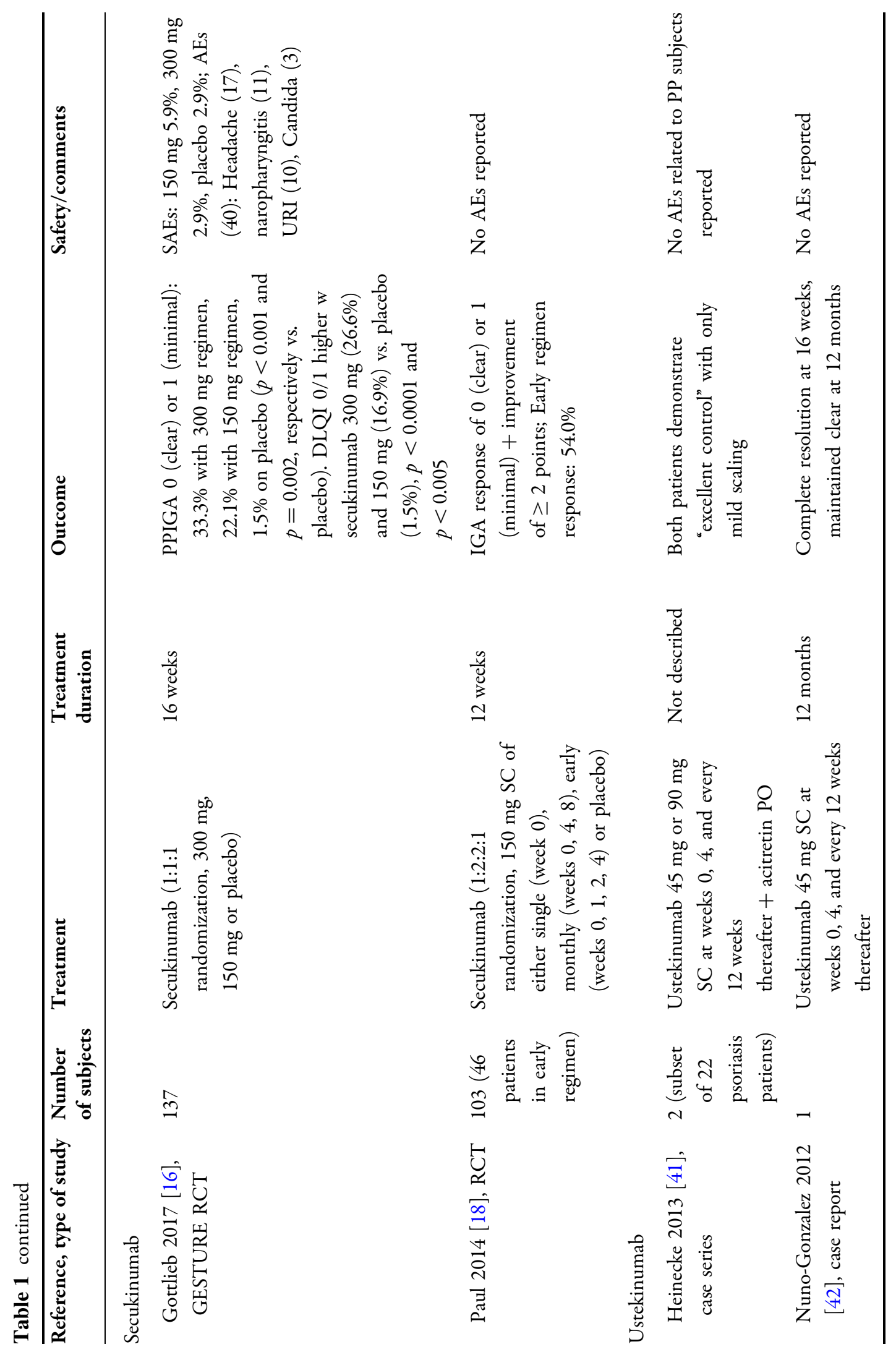




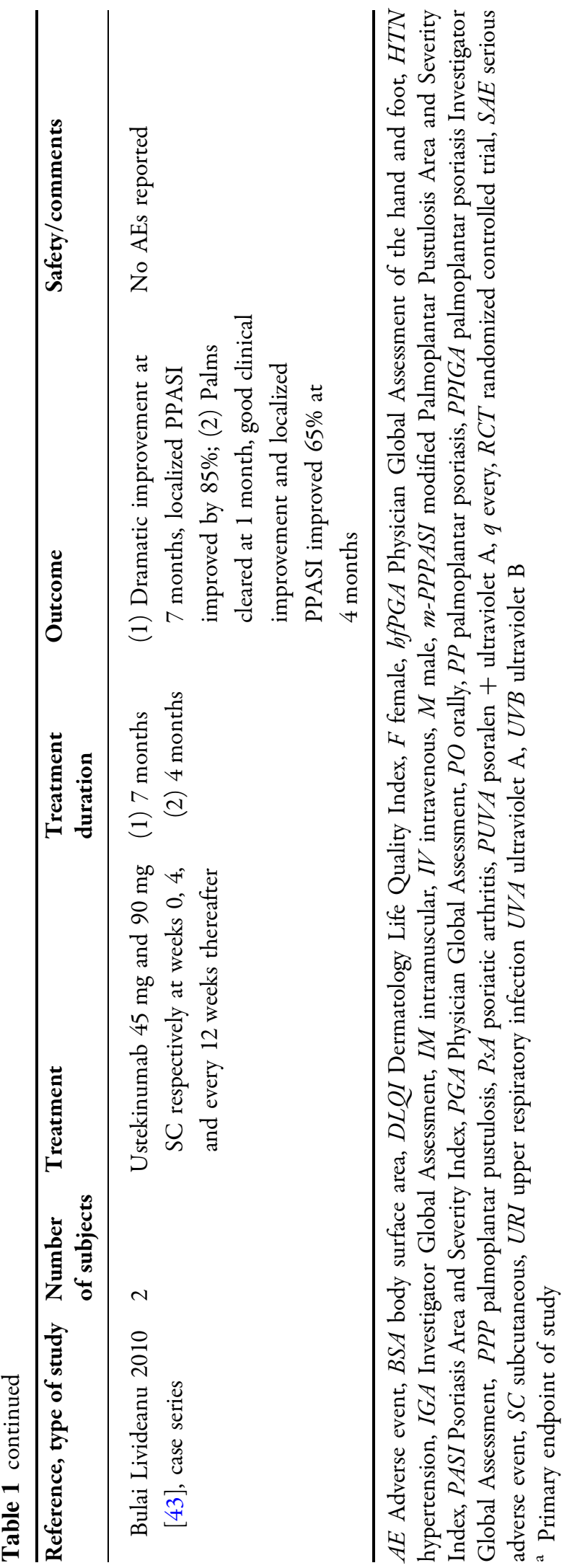

guselkumab. In three phase 3 trials conducted by Menter et al. [17], a greater proportion of the patients treated with ixekizumab showed clinical improvement compared to those treated with etanercept or those receiving placebo (PPASI-50: 80 vs. 67.8 vs. 32.9, respectively; $p<0.05)$. Overall, $82.5 \%$ of the patients studied who were using ixekizumab demonstrated clinical improvement. Significant clinical clearance was achieved in a RCT that compared secukinumab at a dose of 300 or $150 \mathrm{mg}$ to placebo [palmoplantar psoriasis IGA (PPIGA) score of 0 or $1: 33.3 \%$ (300 mg dose), $22.1 \%$ (150 mg dose), vs. $1.5 \% ; p<0.001$ and $p=0.002$, respectively] [16]. The proportion of patients in all studies demonstrating clinical improvement after completing treatment with secukinumab was $89.1 \%$. In an uncontrolled open label study of ustekinumab, $20 \%$ patients with hyperkeratotic PP achieved clinical clearance after 16 weeks of therapy [10]. Clinical clearance was achieved by $50 \%$ of patients receiving a $90 \mathrm{mg}$ dosage regimen, while no patients receiving a $45 \mathrm{mg}$ regimen achieved clearance.

A number of case series and case reports describe effective treatment of hyperkeratotic PP with etanercept, alefacept, infliximab, and ustekinumab (Tables 1, 4) [21, 25, 26, 33, 34, 41-43, 52].

\section{Pustular PP}

In a small RCT by Bissonnette et al. [11], ustekinumab $45 \mathrm{mg}$ was not superior to placebo in achieving at least a 50\% reduction in clinical severity among patients with pustular PP after 16 weeks of therapy $(p=1.00)$. In an open label study by Au et al. [10], half of the patients with pustular PP treated with ustekinumab achieved clinical clearance after 16 weeks of therapy. A greater proportion of patients receiving a $90 \mathrm{mg}$ regimen of ustekinumab achieved clearance compared to those receiving a $45 \mathrm{mg}$ regimen ( $80 \%$ vs. $20 \%)$. In another open label study, $54.5 \%$ of patients with pustular or hyperkeratotic PP who were treated with adalimumab reached clinical clearance after 12 weeks of therapy [19]. 


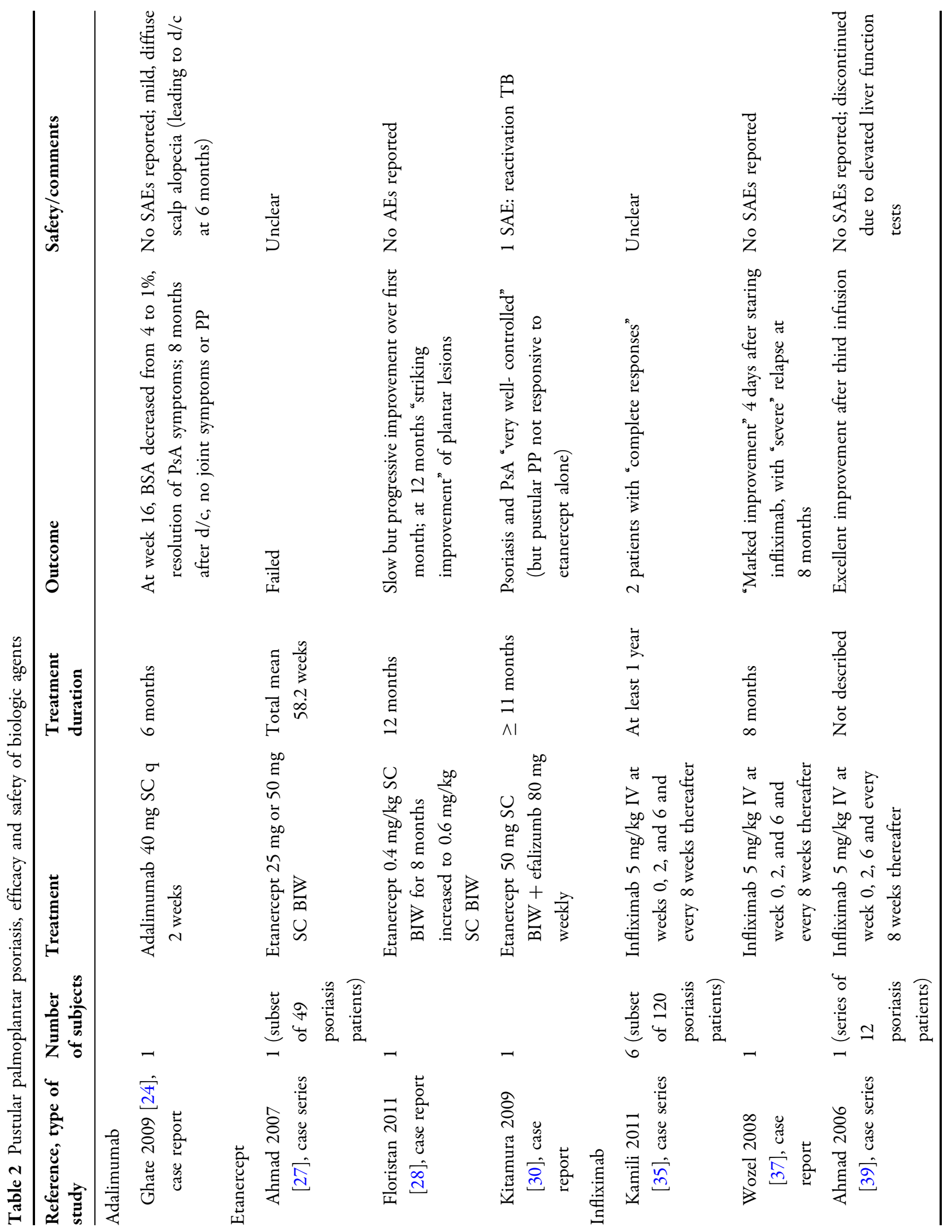




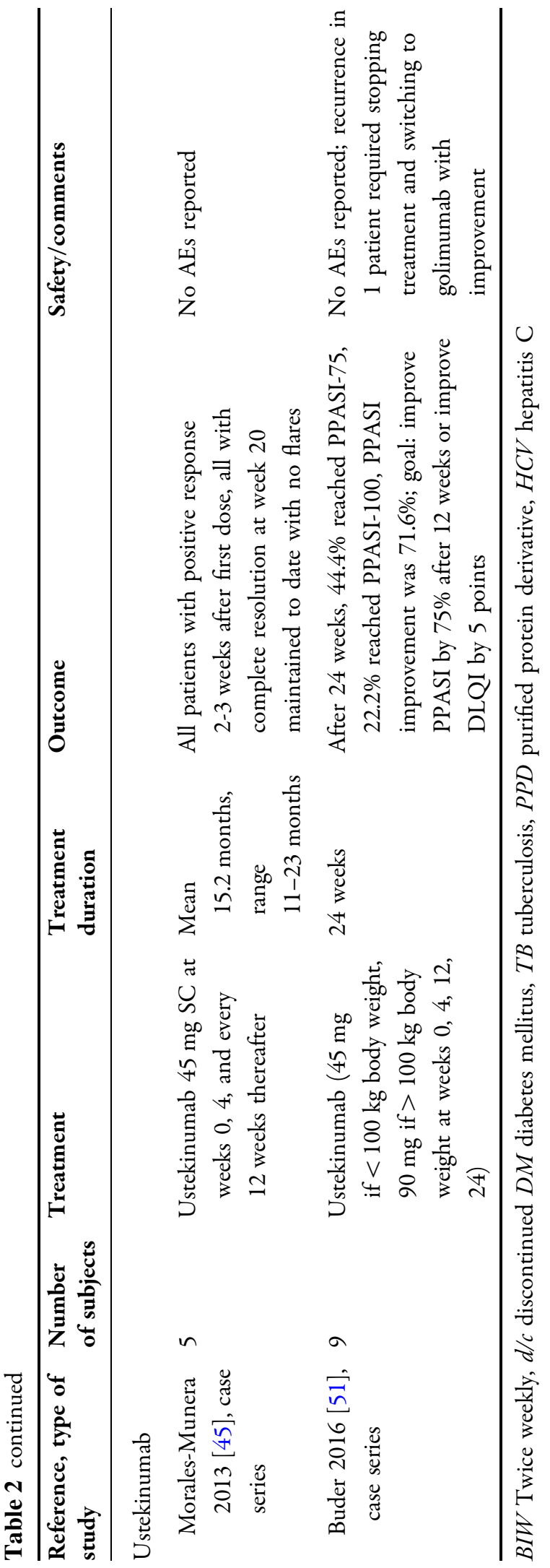

In addition, case series and case reports describe effective treatment of pustular PP with adalimumab, etanercept, infliximab, and ustekinumab

$[24,26,28,30,34,35,37,39,45,51,52,54]$. In contrast, other case reports show ineffective treatment with adalimumab or mixed responses to ustekinumab (Tables 2, 4) $[27,54]$.

\section{Palmoplantar Pustulosis}

In a RCT of patients with PPP conducted by Bissonnette et al. [12], treatment with etanercept was not found to be superior to placebo at the primary endpoint of 12 weeks of therapy $(p=0.426)$. Interestingly, smoking may have played a role in treatment efficacy, as the authors noted that three of three nonsmokers achieved clinical improvement with etanercept therapy while only three of seven active smokers demonstrated improvement. In a small RCT by Bissonnette et al. [11], ustekinumab $45 \mathrm{mg}$ was not found to be superior to placebo at 16 weeks of therapy $(p=1.00)$.

Case reports and case series describe effective treatment of PPP with etanercept, infliximab, and ustekinumab [20, 29, 31, 32, 46-50, 53, 54]. Multiple reports of treatment with infliximab describe a period of initial improvement with eventual recurrence (Tables 3, 4) [36, 38, 40].

\section{Safety}

Serious adverse events (SAEs) were infrequently reported. The majority of cases occurred in patients treated with infliximab, and the SAEs included cellulitis, hepatitis, an urticarial infusion reaction, a serum sickness-like infusion reaction, and autoimmune hepatitis $[13,34,36,38]$. One subject with a history of a positive tuberculin skin test developed reactivation tuberculosis while undergoing treatment with etanercept for pustular PP [30]. In the GESTURE RCT that used secukinumab as treatment for hyperkeratotic PP, 5.9\% of patients developed SAEs while on a $150 \mathrm{mg}$ therapeutic regimen and $2.9 \%$ of patients developed SAEs while on a $300 \mathrm{mg}$ therapeutic regimen, compared to $2.9 \%$ that developed SAEs while using 


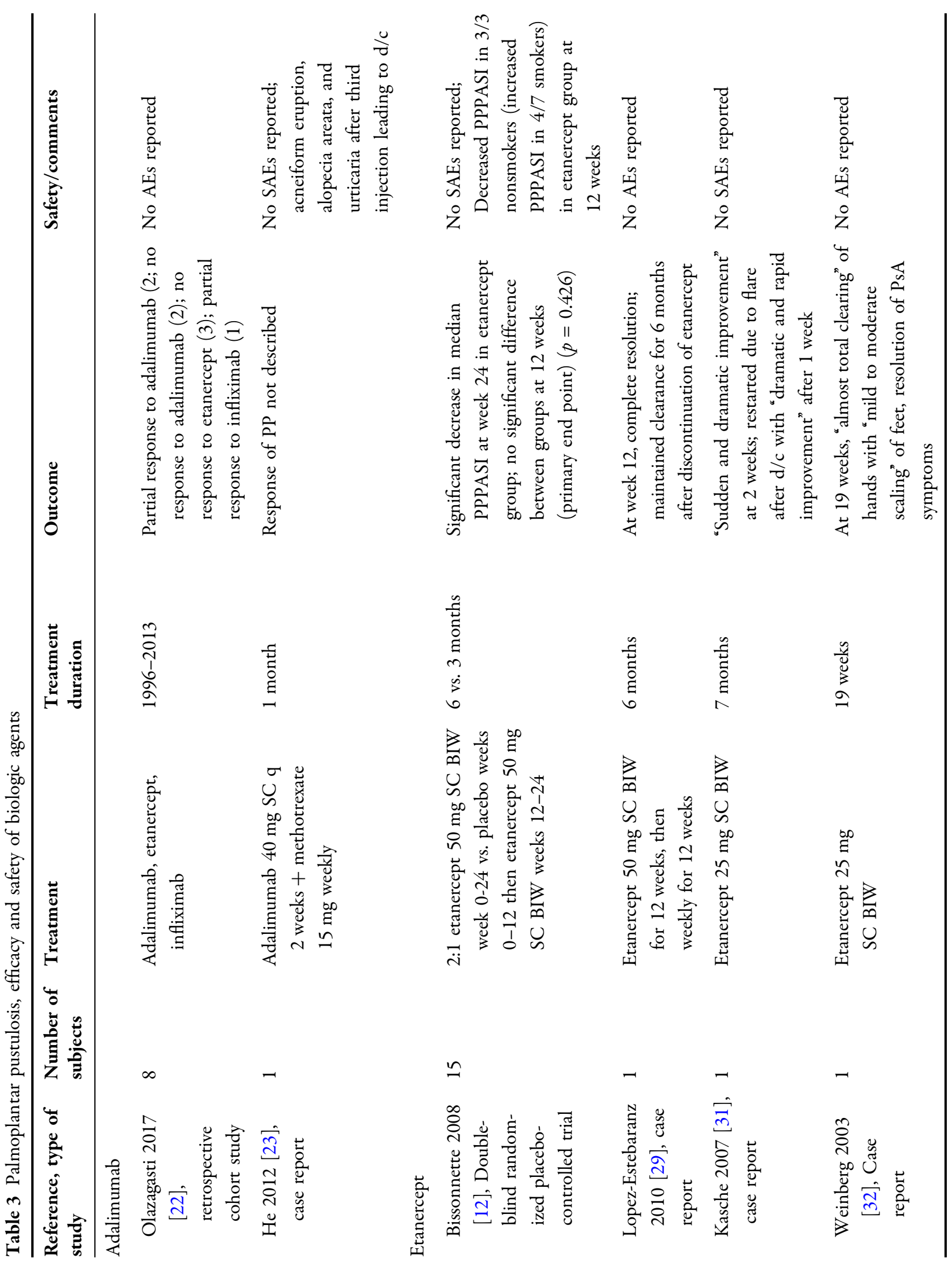




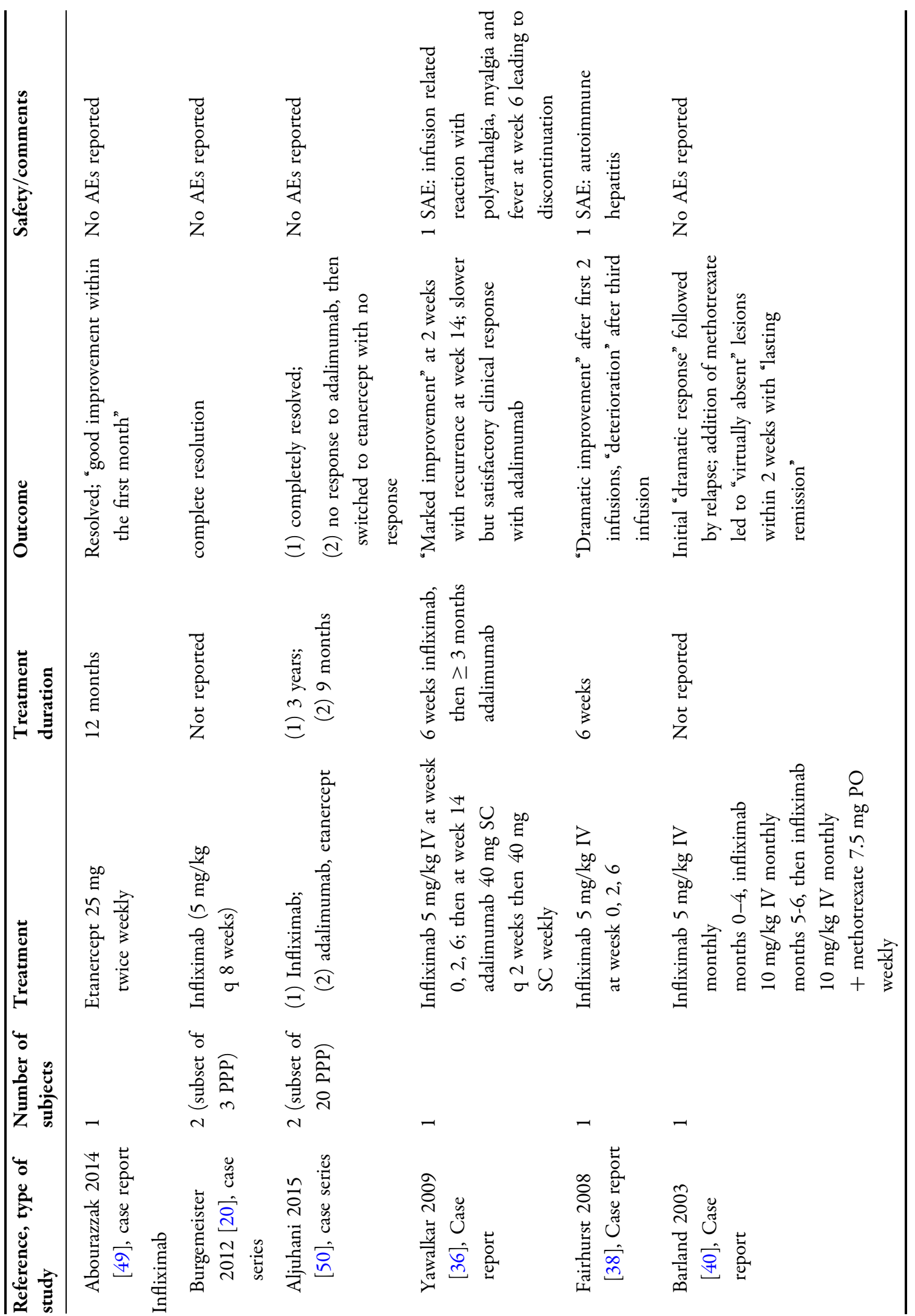




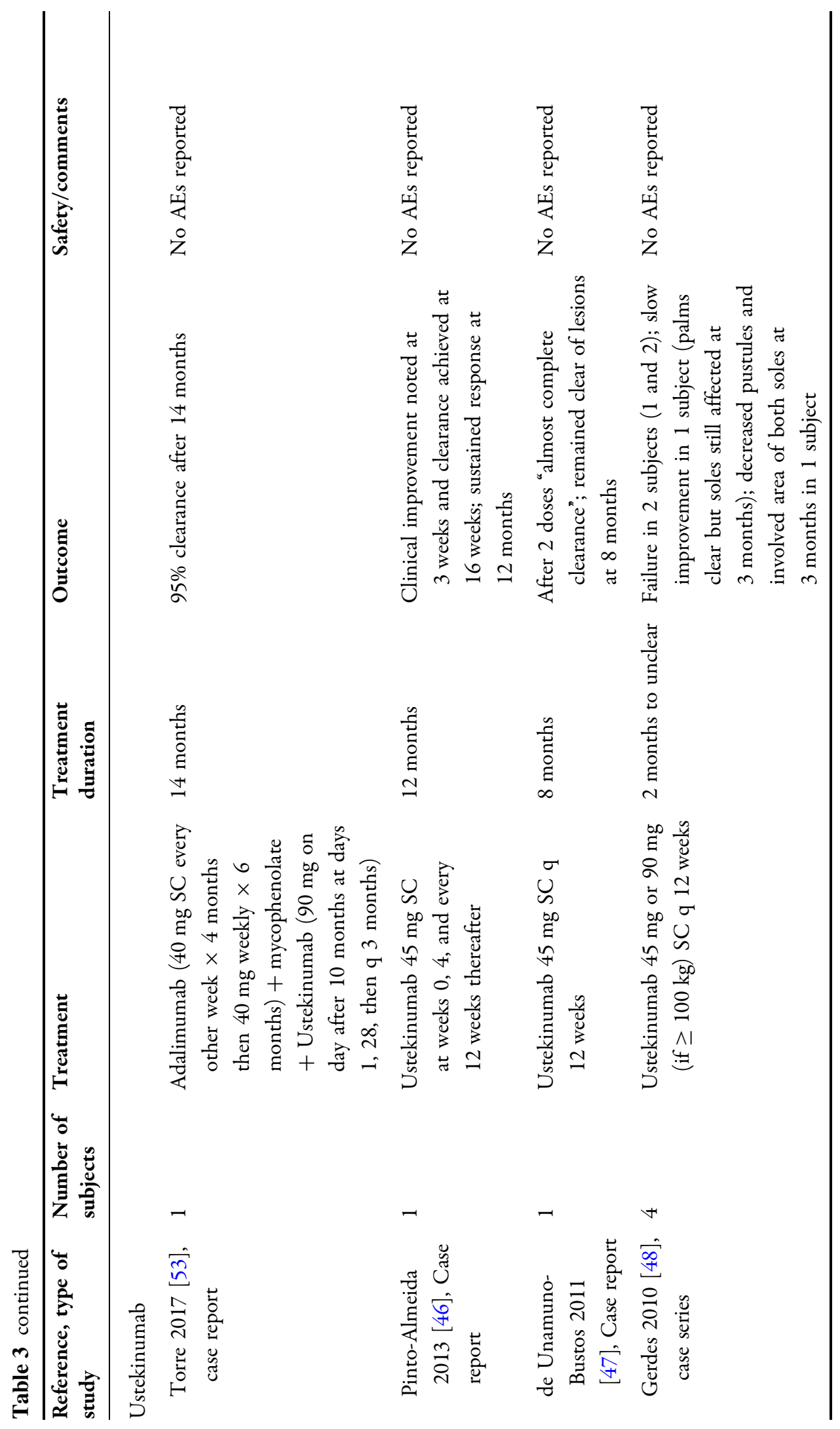




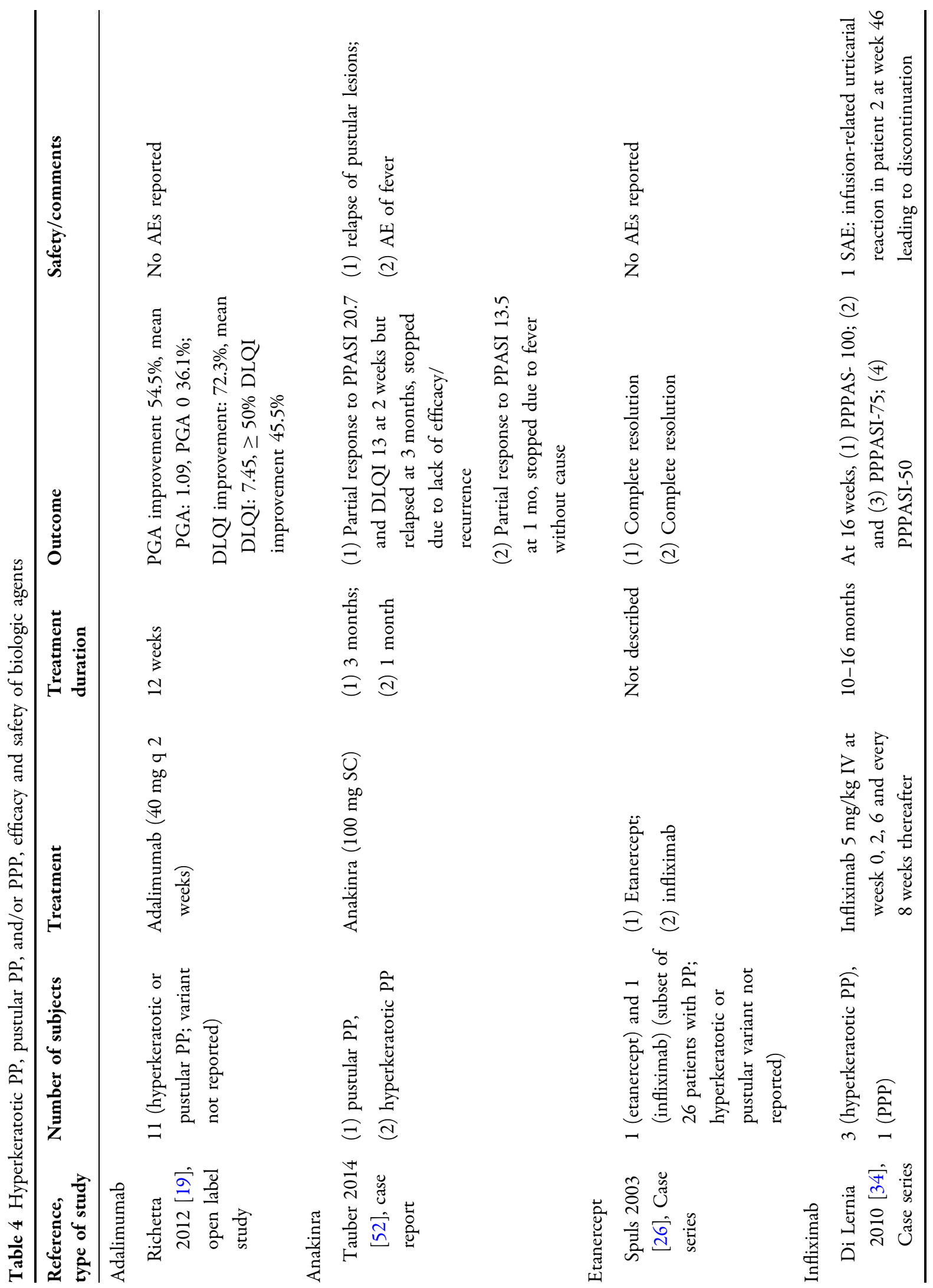




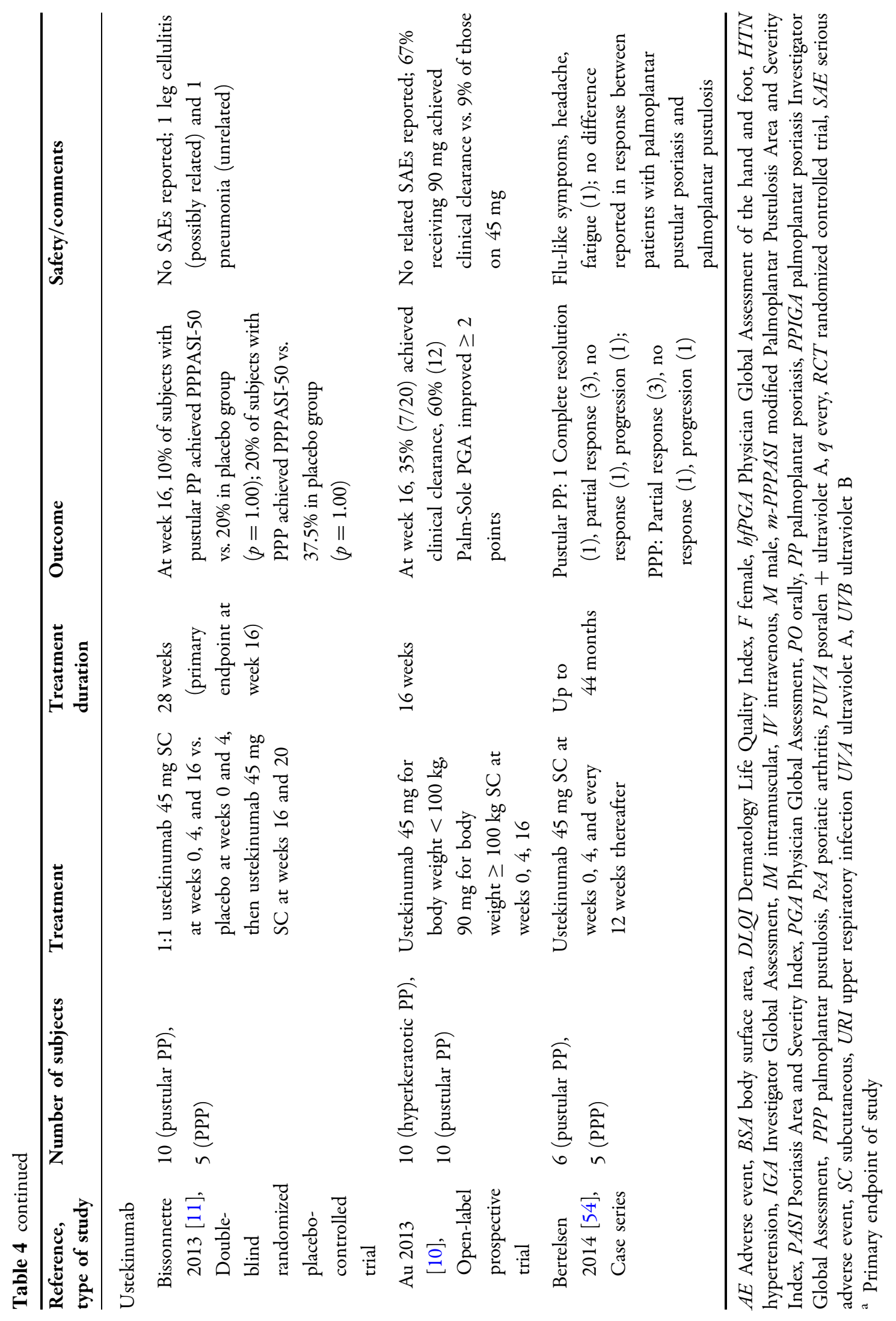


Table 5 Clinical improvement of palmoplantar psoriasis or palmoplantar pustulosis following treatment with biologic agent

\begin{tabular}{|c|c|c|c|c|}
\hline Medication & Variant treated & $\begin{array}{l}\text { Total } \\
\text { number of } \\
\text { cases }\end{array}$ & $\begin{array}{l}\text { Cases in which patients } \\
\text { demonstrated } \\
\text { improvement }^{\mathrm{a}}\end{array}$ & Serious adverse events \\
\hline \multirow[t]{4}{*}{ Adalimumab } & Hyperkeratotic PP $[14,15]$ & 150 & $142(94.7 \%)$ & No SAEs reported \\
\hline & Pustular PP [24] & 1 & $1(100.0 \%)$ & No SAEs reported \\
\hline & PPP $[22,23,50,53]$ & 7 & $2(28.6 \%)$ & No SAEs reported \\
\hline & Total $^{\mathrm{b}}$ & 169 & $152(89.9 \%)$ & \\
\hline \multirow[t]{4}{*}{ Alefacept } & Hyperkeratotic PP [21] & 2 & $2(100.0 \%)$ & No SAEs reported \\
\hline & Pustular PP & 0 & 0 & \\
\hline & PPP & 0 & 0 & \\
\hline & Total & 2 & $2(100.0 \%)$ & \\
\hline \multirow[t]{4}{*}{ Anakinra } & Hyperkeratotic PP [52] & 1 & $1(100.0 \%)$ & No SAEs reported \\
\hline & Pustular PP [52] & 1 & $1(100.0 \%)$ & No SAEs reported \\
\hline & PPP & 0 & 0 & \\
\hline & Total & 2 & $2(100.0 \%)$ & \\
\hline \multirow[t]{4}{*}{ Etanercept } & Hyperkeratotic PP $[17,25]$ & 60 & $41(68.3 \%)$ & No SAEs reported \\
\hline & Pustular PP $[27,28,30]$ & 3 & $2(66.7 \%)$ & Reactivation of latent $\mathrm{TB}$ \\
\hline & $\operatorname{PPP}[12,22,29,31,32,49]$ & 23 & $13(56.5 \%)$ & No SAEs reported \\
\hline & Total $^{\mathrm{b}}$ & 87 & $57(65.5 \%)$ & \\
\hline \multirow[t]{4}{*}{ Guselkumab } & Hyperkeratotic PP [15] & 100 & $90(90.0 \%)$ & No SAEs reported \\
\hline & Pustular PP & 0 & 0 & \\
\hline & PPP & 0 & 0 & \\
\hline & Total & 100 & $90(90.0 \%)$ & \\
\hline \multirow[t]{4}{*}{ Infliximab } & $\begin{array}{c}\text { Hyperkeratotic PP } \\
{[13,33,34]}\end{array}$ & 32 & $24(75.0 \%)$ & $\begin{array}{l}\text { Cellulitis, hepatitis, } \\
\text { infusion-related urticarial } \\
\text { reaction }\end{array}$ \\
\hline & Pustular PP $[35,37,39]$ & 8 & $4(50.0 \%)$ & \\
\hline & $\begin{array}{l}\text { PPP } \\
\quad[20,22,34,36,38,40,50]\end{array}$ & 8 & $8(100.0 \%)$ & $\begin{array}{l}\text { Serum sickness-like infusion } \\
\text { reaction, autoimmune } \\
\text { hepatitis }\end{array}$ \\
\hline & Total $^{\mathrm{b}}$ & 49 & 37 (75.5\%) & \\
\hline
\end{tabular}


Table 5 continued

\begin{tabular}{|c|c|c|c|c|}
\hline Medication & Variant treated & $\begin{array}{l}\text { Total } \\
\text { number of } \\
\text { cases }\end{array}$ & $\begin{array}{l}\text { Cases in which patients } \\
\text { demonstrated } \\
\text { improvement }^{a}\end{array}$ & Serious adverse events \\
\hline \multirow[t]{4}{*}{ Ixekizumab } & Hyperkeratotic PP [17] & 206 & $170(82.5 \%)$ & No SAEs reported \\
\hline & Pustular PP & 0 & 0 & \\
\hline & PPP & 0 & 0 & \\
\hline & Total & 206 & $170(82.5 \%)$ & \\
\hline \multirow[t]{4}{*}{ Secukinumab } & Hyperkeratotic PP $[16,18]$ & 183 & $63(89.1 \%)$ & $\begin{array}{l}150 \mathrm{mg} 5.9 \% \text { SAE, } 300 \mathrm{mg} \\
2.9 \% \text { SAE, placebo } 2.9 \% \\
\mathrm{SAE}^{\mathrm{c}}\end{array}$ \\
\hline & Pustular PP & 0 & 0 & \\
\hline & PPP & 0 & 0 & \\
\hline & Total & 183 & $63(89.1 \%)$ & \\
\hline \multirow[t]{4}{*}{ Ustekinumab } & $\begin{array}{l}\text { Hyperkeratotic PP } \\
{[10,41-43]}\end{array}$ & 15 & $13(86.7 \%)$ & No SAEs reported \\
\hline & $\begin{array}{l}\text { Pustular PP } \\
\qquad[10,11,45,51,54]\end{array}$ & 40 & $22(55.0 \%)$ & No SAEs reported \\
\hline & $\mathrm{PPP}[11,46-48,53,54]$ & 17 & $10(58.8 \%)$ & No SAEs reported \\
\hline & Total & 72 & $45(62.5 \%)$ & \\
\hline
\end{tabular}

$S A E$ serious adverse event

a Using most conservative estimate [PPASI-50 if available; otherwise, if reported, a PPASI-75 or an IGA score of $0 / 1$ (cleared/minimal disease)]

b Includes data from Richetta et al. [19], and Spuls et al. [26] in which specific morphology is not described

c No SAEs were fatal, no cardiac events, and no opportunistic infections

placebo. However, the authors of this study did not report the statistical significance of the SAEs. None of these SAEs were cardiac-related, and there were no opportunistic infections or fatalities [16].

\section{Special Populations}

Three patients with chronic hepatitis $\mathrm{C}$ virus (HCV) were treated with biologic medications for PP without hepatologic complications [30, 34, 45]. One patient with chronic HCV displayed an infusion-related urticarial reaction during infliximab treatment, leading to discontinuation of the medication [34]. One patient with comorbid untreated latent tuberculosis developed reactivation tuberculosis after 4 years of therapy with etancercept [34]. One pediatric patient was treated with etanercept with no reported SAEs [28].

\section{DISCUSSION}

The advent of biologic medications has greatly enhanced the treatment of moderate to severe plaque psoriasis. Current evidence suggests that biologic agents may also be effective therapeutic options for the treatment of hyperkeratotic PP, with less evidence supporting their use in pustular PP and PPP.

For hyperkeratotic PP, results from RCTs (level 1 evidence) suggest that adalimumab, 
guselkumab, ixekizumab, infliximab, and secukinumab are effective treatment options. While ustekinumab has not been evaluated in a RCT of patients with hyperkeratotic PP, in an open label study (level 3 evidence), one-half of patients receiving a $90 \mathrm{mg}$ regimen achieved clinical clearance.

For pustular PP, ustekinumab $45 \mathrm{mg}$ did not appear to be more effective than placebo (level 1 evidence) in patients participating in a small RCT. However, the majority of patients $(80 \%)$ with pustular PP receiving a $90 \mathrm{mg}$ regimen of ustekinumab in an open label study did achieve clinical clearance [10]. With the exception of ustekinumab, limited information on pustular PP treatment can be found in the literature. We found only eight pustular PP patients treated with infliximab, three patients with etanercept, and one patient each treated with adalimumab and anakinra. We found no reports of pustular PP treatment with alefacept, guselkumab, ixekizumab, or secukinumab. Of note, in all of the pustular PP case reports, patients were treated with the standard dose of biologic for plaque psoriasis. The lack of response in many of these cases suggests the possibility that pustular PP may require higher doses of biologics than hyperkeratotic PP or body plaque psoriasis in order to achieve efficacy.

For the treatment of PPP, the results of two small RCTs suggest that treatment with etanercept and ustekinumab $45 \mathrm{mg}$ may not be more effective than placebo (level 1 evidence). However, the study of ustekinumab included only five patients in the active treatment arm, and no patient received a $90 \mathrm{mg}$ regimen of this biologic $[11,54]$. Overall, infliximab appeared to have the greatest efficacy for PPP compared to other biologics, followed by ustekinumab. It is important to note that the quality of these conclusions is limited since most of the data were from case reports or case series.

Although case series and case reports offer less rigorous evidence for the efficacy of biologic agents in PP and PPP, they do illustrate a few notable trends. For example, ustekinumab has been shown to be effective in multiple cases of PP and PPP refractory to tumor necrosis factor-alpha $(\mathrm{TNF}-\alpha)$ inhibitor therapy $[10,43,45,47,48]$. Additionally, infliximab appears to have a higher risk of SAEs compared to other biologics, and it may also demonstrate loss of efficacy over the course of treatment $[13,34,36-38,40]$. In one RCT, patients treated with secukinumab $150 \mathrm{mg}$ showed a greater percentage of SAEs than those receiving placebo ( $5.9 \%$ vs $2.9 \%$, respectively), but there was no dose effect, with the secukinumab $300 \mathrm{mg}$ group having a SAE rate of $2.9 \%$, which was identical to that of the group receiving placebo [16]. These data indicate that secukinumab may not be truly associated with SAEs, since there is not an observable dose-response relationship or trend.

Importantly, while there have been reports of new-onset PPP or exacerbation of existing PPP during TNF- $\alpha$ inhibitor therapy [55-58], only one clearly reported case of exacerbation of PPP, in response to infliximab, was identified in our review of patients with baseline PP and PPP [37]. In one RCT, four patients (40.0\%) with PPP treated with etanercept experienced increases in disease severity over the first 12 weeks of treatment, but it is not clear whether these were drug-induced exacerbations or simply reflective of a nonresponse to treatment and disease progression [12].

Notably, two recent studies based on subanalysis of Phase II data for secukinumab demonstrated high rates of response among patients with hyperkeratotic PP, with up to $71 \%$ of patients achieving clinically significant improvement $[59,60]$. Further studies of novel biologic agents developed for the treatment of moderate to severe plaque psoriasis may yield new therapeutic options for PP and PPP.

The difference in response to biologics observed between PP and PPP may be explained by some notable differences in their genetic profiles. The psoriasis susceptibility gene locus (PSORS1) that is strongly linked to psoriasis is not found in patients with PPP. Additionally, both a missense mutation in the interleukin (IL)-36 receptor antagonist (IL36RN) and caspase recruitment domain family member 14 (CARD14) have been identified in patients with PPP, which could influence patient response to treatment with biologics $[9,61]$. However, both PP and PPP involve IL-17 as a mediator of inflammation, in addition to interferon-gamma 
and TNF- $\alpha$. The shared histologic features of the diseases, consisting of spongiform pustules and inflammatory infiltrates, may account for some of the overlap in treatment response and clinical appearance $[7,9]$. There is a need for future studies to explore these genetic differences further.

Several limitations to our analysis make it difficult to assess the efficacy of biologic medications in PP and PPP. First, patients with PP and PPP are often excluded from clinical trials due to recruitment requirements that patients be diagnosed with stable plaque psoriasis with no pustular component and demonstrate involvement of at least $10 \%$ of the body surface area. Second, some of the RCTs using biologics for these skin diseases, especially for pustular PP, although completed, are not published yet and therefore could not be included in our review. Third, reporting bias in case reports and case series makes it difficult to determine the true rates of response to biologic agents. Fourth, differences in the use of metrics to quantify the severity of PP and PPP impose challenges when comparing rates of response across studies. In addition, only one small RCT was available for pustular PP and another for PPP, with the majority of RCTs specific to hyperkeratotic PP.

Currently, a number of different scales are used to assess the severity of PP and PPP, and in many case reports and case series no metrics are used at all. Future studies should attempt to standardize the heterogeneity of clinical metrics to allow for a more rigorous comparison of the efficacy of biologic medications in PP and PPP. In some RCTs, only mean changes in clinical scores are reported without information on patient-specific responses. In the most basic schema, the number of patients who achieve clearance and the number who demonstrate objective improvement should be reported. Further, studies should consistently report the presence or absence of psoriasis at other body areas and stratify results based on this information.

Nonetheless, patient reported outcomes and functional metrics, such as the survey developed by Farley et al., may be more important than visual metrics in evaluating response to treatment in PP and PPP [5]. Complete clearance may not be necessary if patients achieve sufficient improvement to perform activities of daily living and occupational tasks without pain or discomfort [2].

\section{CONCLUSION}

Overall, biologics are effective and well-tolerated for the treatment of hyperkeratotic PP, as demonstrated by the $>80 \%$ efficacy for adalimumab, guselkumab, ixekizumab, secukinumab, and ustekinumab. The strong support for effective hyperkeratotic PP treatment is derived from multiple large RCTs, and thus providers may consider tailoring their treatment to include biologics earlier when a patient presents with this recalcitrant chronic disease. Infliximab and ustekinumab showed moderate efficacy for pustular PP, but the data were limited to small trials or case reports. Less data are available for the treatment of PPP; however, to date infliximab is the most efficacious treatment. Future studies are needed to further assess the efficacy of biologic medications in the treatment of PP and PPP. In addition, future research should be performed to compare the efficacy and safety of biologics with traditional systemic therapy and phototherapy for these debilitating and therapeutically challenging conditions.

\section{ACKNOWLEDGEMENTS}

No funding or sponsorship was received for this study or publication of this article. All named authors meet the International Committee of Medical Journal Editors (ICMJE) criteria for authorship for this manuscript, take responsibility for the integrity of the work as a whole, and have given final approval for the version to be published.

Disclosures. I. Sanchez, E. Sorenson, and E. Levin have nothing to disclose. W. Liao has received research funding from AbbVie, Janssen, Novartis, and Pfizer. 
Compliance with Ethics Guidelines. This article is based on previously conducted studies and does not involve any new studies of human or animal subjects performed by any of the authors.

Open Access. This article is distributed under the terms of the Creative Commons Attribution-NonCommercial 4.0 International License (http://creativecommons.org/licenses/ by-nc/4.0/), which permits any noncommercial use, distribution, and reproduction in any medium, provided you give appropriate credit to the original author(s) and the source, provide a link to the Creative Commons license, and indicate if changes were made.

\section{REFERENCES}

1. Kumar B, Saraswat A, Kaur I. Palmoplantar lesions in psoriasis: a study of 3065 patients. Acta Derm Venereol. 2002;82(3):192-5.

2. Pettey AA, Balkrishnan R, Rapp SR, Fleischer AB, Feldman SR. Patients with palmoplantar psoriasis have more physical disability and discomfort than patients with other forms of psoriasis: implications for clinical practice. J Am Acad Dermatol. 2003;49(2):271-5.

3. Adisen E, Tekin O, Gulekon A, Gurer MA. A retrospective analysis of treatment responses of palmoplantar psoriasis in 114 patients. J Eur Acad Dermatol Venereol. 2009;23(7):814-9.

4. Griffiths CE, Christophers E, Barker JN, et al. A classification of psoriasis vulgaris according to phenotype. Br J Dermatol. 2007;156(2):258-62.

5. Farley E, Masrour S, McKey J, Menter A. Palmoplantar psoriasis: a phenotypical and clinical review with introduction of a new quality-of-life assessment tool. J Am Acad Dermatol. 2009;60(6):1024-31.

6. Bolognia J, Jorizzo JL, Schaffer JV, editors. Dermatology. 3rd ed. Toronto: Elsevier Canada; 2012.

7. Raposo I, Torres T. Palmoplantar psoriasis and palmoplantar pustulosis: current treatment and future prospects. Am J Clin Dermatol. 2016;17(4):349-58.

8. Engin B, Askin O, Tuzun Y. Palmoplantar psoriasis. Clin Dermatol. 2017;35(1):19-27.
9. Asumalahti K, Ameen M, Suomela S, et al. Genetic analysis of PSORS1 distinguishes guttate psoriasis and palmoplantar pustulosis. J Invest Dermatol. 2003;120(4):627-32.

10. Au SC, Goldminz AM, Kim N, et al. Investigator-initiated, open-label trial of ustekinumab for the treatment of moderate-to-severe palmoplantar psoriasis. J Dermatol Treat. 2013;24(3):179-87.

11. Bissonnette R, Nigen S, Langley RG, et al. Increased expression of IL-17A and limited involvement of IL-23 in patients with palmo-plantar (PP) pustular psoriasis or PP pustulosis; results from a randomised controlled trial. J Eur Acad Dermatol Venereol. 2014;28(10):1298-305.

12. Bissonnette R, Poulin Y, Bolduc C, et al. Etanercept in the treatment of palmoplantar pustulosis. J Drugs Dermatol. 2008;7(10):940-6.

13. Bissonnette R, Poulin Y, Guenther L, Lynde CW, Bolduc C, Nigen S. Treatment of palmoplantar psoriasis with infliximab: a randomized, double-blind placebo-controlled study. J Eur Acad Dermatol Venereol. 2011;25(12):1402-8.

14. Leonardi C, Langley RG, Papp K, et al. Adalimumab for treatment of moderate to severe chronic plaque psoriasis of the hands and feet: efficacy and safety results from REACH, a randomized, placebo-controlled, double-blind trial. Arch Dermatol. 2011;147(4):429-36.

15. Blauvelt A, Papp KA, Griffiths CE, et al. Efficacy and safety of guselkumab, an anti-interleukin-23 monoclonal antibody, compared with adalimumab for the continuous treatment of patients with moderate to severe psoriasis: results from the phase III, double-blinded, placebo- and active comparator-controlled VOYAGE 1 trial. J Am Acad Dermatol. $2017 ; 76(3): 405-17$.

16. Gottlieb A, Sullivan J, van Doorn M, et al. Secukinumab shows significant efficacy in palmoplantar psoriasis: results from GESTURE, a randomized controlled trial. J Am Acad Dermatol. 2017;76(1):70-80.

17. Menter A, Warren RB, Langley RG, et al. Efficacy of ixekizumab compared to etanercept and placebo in patients with moderate-to-severe plaque psoriasis and non-pustular palmoplantar involvement: results from three phase 3 trials (UNCOVER-1, UNCOVER-2 and UNCOVER-3). J Eur Acad Dermatol Venereol. 2017;31(10):1686-92.

18. Paul C, Reich K, Gottlieb AB, et al. Secukinumab improves hand, foot and nail lesions in moderate-to-severe plaque psoriasis: subanalysis of a randomized, double-blind, placebo-controlled, 
regimen-finding phase 2 trial. J Eur Acad Dermatol Venereol. 2014;28(12):1670-5.

19. Richetta AG, Mattozzi C, Giancristoforo S, et al. Safety and efficacy of Adalimumab in the treatment of moderate to severe palmo-plantar psoriasis: an open label study. Clin Ter. 2012;163(2):e61-6.

20. Burgemeister LT, Baeten DL, Tas SW. Biologics for rare inflammatory diseases: TNF blockade in the SA PHO syndrome. Neth J Med. 2012;70(10):444-9.

21. Myers W, Christiansen L, Gottlieb AB. Treatment of palmoplantar psoriasis with intramuscular alefacept. J Am Acad Dermatol. 2005;53[2 Suppl 1]:S127-9.

22. Olazagasti JM, Ma JE, Wetter DA. Clinical features, etiologic factors, associated disorders, and treatment of palmoplantar pustulosis: the Mayo clinic experience, 1996-2013. Mayo Clin. Proc. 2017;92(9):1351-8.

23. He GY, Tsai TF. Concomitant occurrence of acneiform eruption, alopecia areata, and urticaria during adalimumab treatment in a patient with pustulosis palmoplantaris: case report and literature review. Dermatol Sin. 2012;30(2):51-6.

24. Ghate JV, Alspaugh CD. Adalimumab in the management of palmoplantar psoriasis. J Drugs Dermatol. 2009;8(12):1136-9.

25. Meyer V, Goerge T, Luger TA, Beissert S. Successful treatment of palmoplantar hyperkeratotic psoriasis with a combination of etanercept and alitretinoin. J Clin Aesthet Dermatol. 2011;4(4):45-6.

26. Spuls PI, Hadi S, Rivera L, Lebwohl M. Retrospective analysis of the treatment of psoriasis of the palms and soles. J Dermatol Treatm. 2003;14[Suppl 2]:21-5.

27. Ahmad K, Rogers S. Two years of experience with etanercept in recalcitrant psoriasis. Br J Dermatol. 2007;156(5):1010-4.

28. Floristan U, Feltes R, Ramirez P, Alonso ML, De Lucas R. Recalcitrant palmoplantar pustular psoriasis treated with etanercept. Pediatr Dermatol. 2011;28(3):349-50.

29. Lopez-Estebaranz JL, Ruiz-Genao D. Pustular psoriasis, palmoplantar psoriasis, erythodermal psoriasis and etanercept. Actas Dermosifiliogr. 2010;101[Suppl 1]:35-9.

30. Kitamura G, Mehr N, Anderson N, Sirichotiratana $\mathrm{M}$. A case of tuberculosis in a patient on efalizumab and etanercept for treatment of refractory palmopustular psoriasis and psoriatic arthritis. Dermatol Online J. 2009;15(2):11.
31. Kasche A, Pfab F, Hein R, et al. Severe psoriasis pustulosa palmaris et plantaris (Barber-Konigsbeck) treated successfully with soluble tumour necrosis factor receptor fusion protein (etanercept). J Eur Acad Dermatol Venereol. 2007;21(2):255-7.

32. Weinberg JM. Successful treatment of recalcitrant palmoplantar psoriasis with etanercept. Cutis. 2003;72(5):396-8.

33. Brunasso AM, Puntoni M, Delfino C, Massone C. Different response rates between palmoplantar involvement and diffuse plaque psoriasis in patients treated with infliximab. Eur J Dermatol. 2012;22(1):133-5.

34. Di Lernia V, Guareschi E. Successful treatment of hand and foot psoriasis with infliximab. Dermatol Online J. 2010;16(7):8.

35. Kamili QU, Miner A, Hapa A, Menter A. Infliximab treatment for psoriasis in 120 patients on therapy for a minimum of one year: a review. J Drugs Dermatol. 2011;10(5):539-44.

36. Yawalkar N, Hunger RE. Successful treatment of recalcitrant palmoplantar pustular psoriasis with sequential use of infliximab and adalimumab. Dermatology. 2009;218(1):79-83.

37. Wozel G, Vitez L. Palmoplantar pustular psoriasis: successful therapy with efalizumab after non-response to infliximab. Acta Derm Venereol. 2008;88(2):169-70.

38. Fairhurst DA, Sheehan-Dare R. Autoimmune hepatitis associated with infliximab in a patient with palmoplantar pustular psoriaisis. Clin Exp Dermatol. 2009;34(3):421-2.

39. Ahmad K, Rogers S. Three years' experience with infliximab in recalcitrant psoriasis. Clin Exp Dermatol. 2006;31(5):630-3.

40. Barland C, Kerdel FA. Addition of low-dose methotrexate to infliximab in the treatment of a patient with severe, recalcitrant pustular psoriasis. Arch Dermatol. 2003;139(7):949-50.

41. Heinecke GM, Luber AJ, Levitt JO, Lebwohl MG. Combination use of ustekinumab with other systemic therapies: a retrospective study in a tertiary referral center. J Drugs Dermatol. 2013;12(10):1098-102.

42. Nuno-Gonzalez A, Gomez de la Fuente E, Vicente-Martin FJ, Lopez-Estebaranz JL. Good response of hyperkeratotic palmoplantar psoriasis to ustekinumab. Acta Dermosifiliogr. 2012;103(2):169-70.

43. Bulai Livideanu C, Lahfa M, Mazereeuw-Hautier J, Paul C. Efficacy of ustekinumab in palmoplantar psoriasis. Dermatology. 2010;221(4):321-3. 
44. Bertelsen $\mathrm{T}$, Kragballe $\mathrm{K}$, Johansen C, Iversen L. Efficacy of ustekinumab in palmoplantar pustulosis and palmoplantar pustular psoriasis. Int J Dermatol. 2014;53(10):e464-6.

45. Morales-Munera C, Vilarrasa E, Puig L. Efficacy of ustekinumab in refractory palmoplantar pustular psoriasis. Br J Dermatol. 2013;168(4):820-4.

46. Pinto-Almeida T, Torres T, Sanches M, Selores M. Treatment of palmoplantar pustulosis with ustekinumab - the importance of interfering with the IL23/Th17 pathway. Eur J Dermatol. 2013;23(6):916-7.

47. de Unamuno-Bustos B, Ballester-Sanchez R, Oliver-Martinez V, Alegre de Miquel V. Ustekinumab for the treatment of palmar-plantar pustulosis. Acta Dermosifiliogr. 2011;102(10):833-5.

48. Gerdes S, Franke J, Domm S, Mrowietz U. Ustekinumab in the treatment of palmoplantar pustulosis. Br J Dermatol. 2010;163(5):1116-8.

49. Abourazzak FE, Hachimi H, Kadi N, Berrada K, Tizniti S, Harzy T. Etanercept in the treatment of SAPHO syndrome: which place? Eur J Rheumatol. 2014;1(3):125-8.

50. Aljuhani F, Tournadre A, Tatar Z, et al. The SAPHO syndrome: a single-center study of 41 adult patients. J Rheumatol. 2015;42(2):329-34.

51. Buder V, Herberger K, Jacobi A, Augustin M, Radtke MA. Ustekinumab in the treatment of palmoplantar pustular psoriasis - a case series of nine patients. J Dtsch Dermatol Ges. 2016;14(11):1108-13.

52. Tauber M, Viguier M, Alimova E, et al. Partial clinical response to anakinra in severe palmoplantar pustular psoriasis. $\mathrm{Br} \quad \mathrm{J}$ Dermatol. 2014;171(3):646-9.

53. Torre KM, Payette MJ. Combination biologic therapy for the treatment of severe palmoplantar pustulosis. JAAD Case Rep. 2017;3(3):240-2.
54. Bertelsen T, Kragballe K, Johansen C, Iversen L. Efficacy of ustekinumab in palmoplantar pustulosis and palmoplantar pustular psoriasis. Int J Dermatol. 2014;53(10):e464-6.

55. de Gannes GC, Ghoreishi M, Pope J, et al. Psoriasis and pustular dermatitis triggered by TNF-\{alpha\} inhibitors in patients with rheumatologic conditions. Arch Dermatol. 2007;143(2):223-31.

56. Heymann WR. Tumor necrosis factor inhibitor-induced pustular psoriasis? J Am Acad Dermatol. 2007;56(2):327-9.

57. Ko JM, Gottlieb AB, Kerbleski JF. Induction and exacerbation of psoriasis with TNF-blockade therapy: a review and analysis of 127 cases. J Dermatol Treatm. 2009;20(2):100-8.

58. Michaelsson G, Kajermo U, Michaelsson A, Hagforsen E. Infliximab can precipitate as well as worsen palmoplantar pustulosis: possible linkage to the expression of tumour necrosis factor-alpha in the normal palmar eccrine sweat duct? Br J Dermatol. 2005;153(6):1243-4.

59. Paul C, Reich K, Gottlieb AB, et al. Secukinumab improves hand, foot and nail lesions in moderate-to-severe plaque psoriasis: subanalysis of a randomized, double-blind, placebo-controlled, regimen-finding phase 2 trial. J Eur Acad Dermatol Venereol. 2014; 28(12):1670-5.

60. Sigurgeirsson B, Kircik L, Nemoto O, et al. Secukinumab improves the signs and symptoms of moderate-to-severe plaque psoriasis in subjects with involvement of hands and/or feet: subanalysis of a randomized, double-blind, placebo-controlled, phase 2 dose-ranging study. J Eur Acad Dermatol Venereol. 2014;28(8):1127-9.

61. Prieto-Perez R, Cabaleiro T, Dauden E, Ochoa D, Roman M, Abad-Santos F. Genetics of psoriasis and pharmacogenetics of biological drugs. Autoimmune Dis. 2013;2013:613086. 